\title{
PENGARUH DEBT TO EQUITY RATIO (DER), DAN \\ RETURN ON ASSET (ROA) TERHADAP HARGA SAHAM PADA \\ PT. AKASHA WIRA INTERNATIONAL, TBK
}

\author{
Hadijah Febriana \\ Megalana Setya Ayati
}

Dosen Dan Mahasiswa Universitas Pamulang

dosen02182@unpam.ac.id,megalanasetya@gmail.com

\begin{abstract}
ABSTRAK
Riset ini untuk melihat efek "Debt to Equity Ratio" dan "Returun On Asset" atas "Harga Saham" di PT. Akasha Wira International, Tbk dengan metode penelitian kuantitatif. Olah data menggunakan SPSS dan menganalisis data dengan uji asumsi klasik, regresi, koefisien determinasi, dan hipotesis. Berdasarkan uji t parsial diperoleh hasil t hitung $D E R$ yaitu thitung $0,376<\mathrm{t}_{\text {tabel }} 2,30600$ yang artinya tidak terdapat efek atas "Harga Saham". Untuk $\mathrm{t}$ hitung ROA $\mathrm{t}_{\text {hitung }}$ 3,199 $>\mathrm{t}_{\text {tabel }}$ 2,30600 berarti terdapat efek atas "Harga Saham". Kemudian hasil $\mathrm{F}$ hitung sebesar 7,886 > 4,459 ,dapat diartikan adanya efek antara "Debt to Equity Ratio" dan "Returun On Asset" atas "Harga Saham"
\end{abstract}

Kata Kunci: Debt to Equity Ratio, Return On Asset, dan Harga Saham

\section{ABSTRACT}

This research is to see the effect of "Debt to Equity Ratio" and "Return on Assets" on the "Stock Price" at PT. Akasha Wira International, Tbk with quantitative research methods. The Data was processed using SPSS and analyzed the data with the classical assumption test, regression, coefficient of determination, and hypothesis. Based on the partial $t$-test, the result of the DER are -0.376 <ttable 2.30600, which means that there is no effect on the "Stock Price". For t count ROA tcount 3.199> ttable 2.30600 means that there is an effect on "Stock Prices". Then the result of $F$ count is 7.886> 4.459, it can be interpreted that there is an effect between "Debt to Equity Ratio" and "Return on Assets" on the "Stock Price".

Keywords: Debt to Equity Ratio, Current Ratio and Return On Equity

I. PENDAhULUAN

A. Latar Belakang

Kondisi perekonomian merupakan suatu hal sangat penting untuk diperhatikan. Banyak perusahaan yang mengalami kebangkrutan dikarenakan efek dari kondisi perekonomian yang tidak menentu. Perusahaan baik skala kecil atau besar harus mempunyai perhatian besar pada perkembangan posisi keuangan di 
JRNAL ПММАH

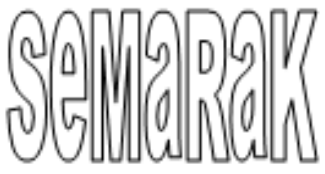

P-ISSN 2615-6849, E-ISSN 2622-3686

Jurnal Semarak,Vol.4,No.2,Juni 2021, Hal (60-66) perusahaannya. Pasar modal dapat meningkatkan perekonomian disebuah negara, karena dengan adanya pasar modal akan ada kegiatan penanaman modal untuk meningkatkan penjualan guna memperoleh laba dan memperbaiki kinerja perusahaan.

PT. Akasha Wira Internasional, Tbk adalah penyedia produk sekaligus penyalur air minum kemasan. Perusahaan ini juga memiliki bisnis kosmetika. Dengan produk yang dimiliki, memberikan dampak adanya persaingan antara perusahaan yang sejenis sehingga perlu diperhatikan kinerja perusahaan. Terlihat dari laporan keuangan PT. Akasha Wira Internasional, Tbk, terdapat kecenderungan penurunan atau kenaikan harga saham dari tahun ketahun.

\section{Tabel 1}

Data Laporan Keuangan

\begin{tabular}{|c|c|c|c|c|c|}
\hline antan & Hesel & 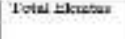 & Gobah Pintah & Wothat Met & $\begin{array}{l}\text { Hane } \\
\text { anten. }\end{array}$ \\
\hline 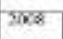 & Re 139117 & RP 5130 & $8 n-15,388$ & 80.585075 & $\beta_{n}=26$ \\
\hline 560 & $2,110 \mathrm{mat}$ & 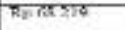 & का. 16 ग & 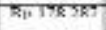 & रिगका \\
\hline $\min$ & शरनानान & Trequan & कर जाटान & करतशनण & קp \\
\hline 2011 & 20.100502 & म5. 123.348 & 20,23365 & क्रिजारण & 34.1010 \\
\hline $20: 2$ & $40.1 \% 9.2$ & Ho.JuXY2 & 40.35376 & और & P.12: \\
\hline $201 x$ & $24.1 / 6.256$ & Ho. 284.78 & Mp. 250 st & S4. +41.064 & Ses 0000 \\
\hline $20 \leq 4$ & $R_{p}-200066$ & $R_{5} .2 / 2090$ & $30,3102 i$ & $R_{v} 50<865$ & $K_{v}, 19 ?$ \\
\hline काज & $K_{1}+324205$ & 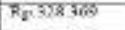 & $51,35 \times 3$ & Fv 8525 & Folise \\
\hline ज्ञात & हर 7 करता & कि दहत दबार & कर दडखरा & कर 7 का तक & कर 1000 \\
\hline कान & रिनान्स & मकाया & कि नारगा2 & 20310216 & xpess \\
\hline 2018 & Rv. 905901 & $R_{g}-51314$ & $R_{v}, 52058$ & $R_{v} 581.275^{7}$ & Rv 520 \\
\hline
\end{tabular}

Tabel 2

DER,ROA dan Harga Saham

\begin{tabular}{|c|c|c|c|}
\hline Tahun & $\begin{array}{c}\text { DER } \\
\text { (kali) }\end{array}$ & $\begin{array}{c}\text { ROA } \\
(\%)\end{array}$ & $\begin{array}{c}\text { Harga Saham } \\
(\text { Rp) }\end{array}$ \\
\hline 2008 & 2,56 & $-8,21 \%$ & 210 \\
\hline 2009 & 1,61 & $9,15 \%$ & 590 \\
\hline 2010 & 2,24 & $9,75 \%$ & 1620 \\
\hline 2011 & 1,51 & $8,18 \%$ & 1010 \\
\hline 2012 & 0,86 & $21,42 \%$ & 1920 \\
\hline 2013 & 0,66 & $12,59 \%$ & 2000 \\
\hline 2014 & 0,70 & $6,14 \%$ & 1375 \\
\hline 2015 & 0,98 & $5,02 \%$ & 1015 \\
\hline 2016 & 0,99 & $7,29 \%$ & 1000 \\
\hline 2017 & 0,98 & $4,55 \%$ & 885 \\
\hline 2018 & 0,82 & $6,00 \%$ & 920 \\
\hline Swrober.idr.coid/data diolah (2020)
\end{tabular}

Tabel 2 menunjukkan permasalahan yang terjadi adanya ketidak stabilan antara "Debt to Equity Ratio", "Returun On Asset" dan "Harga Saham" tahun 2008 hingga 2018. Jika rasio terjadi perubahan, maka akan berpengaruh kepada rasio lainnya. Dalam mengambil keputusan seorang pimpinan perusahaan harus memperhatikan keadaan perusahaannya. Seorang pimpinan perusahaan harus mengambil langkah yang tepat agar mampu meningkatkan profit.

Berkaitan dengan pembahasan sebelumnya, peneliti menetapkan judul "Pengaruh Debt to Equity Ratio (DER), Dan Return On Asset (ROA) terhadap Harga Saham PT. Akasha Wira International, Tbk Tahun 2008 - 2018".

\section{B. Rumusan Masalah.}

1. Bagaimana efek "debt to equity ratio" atas "harga saham" di PT. Akasha Wira International Tbk?

2. Bagaiimana efek"return on asset" atas"harga saham" di PT. Akasha Wira International Tbk?

3. Bagaimaana efek "debt to equity ratio" dan "return on asset" secara simultan atas "harga saham" di PT. Akasha Wira International Tbk?

\section{TINJAUAN PUSTAKA}

\section{A. Laporan Keuangan}

Harahap (2013:105) menyatakan "laporan keuangan menggambarkan kondisi keuangan perusahaan pada saat tertentu". "laporan keuangan adalah laporan yang menunjukkan kondisi keuangan pada waktu ini atau dalam kurun waktu tertentu (Kasmir 2013:7)”.

Bersumber dari penafsiran di atas, laporaan keuangan dimanfaatkan sebagai media informasi mengenai data keuangan untuk manajemen atau pimpinan dalam rangka pengambil keputusan.

\section{B. Rasio Keuangan}

"Rasio keuangan merupakan kegiatan membandingkan angka-angka yang ada di dalam laporan keuangan.Perbandingan dapat dilakukan antara satu komponen dengan komponen 
JRNAL ПММАH

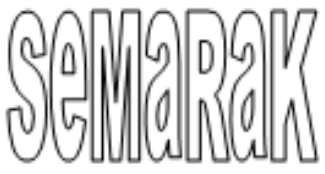

P-ISSN 2615-6849, E-ISSN 2622-3686

Jurnal Semarak,Vol.4,No.2,Juni 2021, Hal (60-66) dalam satu laporan keuangan atau antar komponen yang ada di antara laporan keuangan.Kemudian, angka yang diperbandingkan dapat berupa angkaangka dalam satu periode maupun beberapa periode (Kasmir 2014:104)."

\section{Rasio Solvabilitas}

Dalam hal rasio, Kasmir (2019:112) menyatakan "Rasio Solvabilitas (Leverage Ratio) merupakan rasio yang mampu mengukur sejauh mana aktiva perusahaan dibiayai dengan utang. Artinya, berapa besar beban utang yang ditanggung perusahaan dibandingkan dengan aktivanya." Penulis menggunakan rasio "Debt to Equity Ratio" untuk menaksir solvabilitas. Adapun rumusnya:

DER $=\frac{\text { Total } \text { Hutang }}{\text { Ekuitas }}$

\section{Rasio Profitabilitas}

"Rasio profitabilitas sebagai alat ukur kemampuan perusahaan dengan menggunakan seluruh aktiva yang dimiliki untuk menghasilkan laba dengan menggunakan sumber-sumber yang dimiliki perusahaan, seperti aktiva, modal, atau penjualan perusahaan (Sudana 2011:22)".

Fahmi (2015:135) dalam bukunya mengatakan, "rasio profitabilitas adalah rasio yang mampu menghitung efektivitas manajemen secara keseluruhan yang difokuskan oleh besar kecilnya tingkat keuntungan yang diperoleh dalam hubungannya dengan penjualan maupun investasi”.

Penulis menggunakan "Return On Asset" untuk mengukur Profitabisitas. Rumus:

$R O A=\underline{\text { Net Income }}$

Total Assets

\section{E. Harga Saham}

Menurut Darmadji (2012:102),

"Harga yang terjadi di bursa pada waktu tertentu. Harga saham bisa berubah naik atau pun turun dalam hitungan waktu yang begitu cepat.Ia dapat berubah dalam hitungan menit bahkan dapat berubah dalam hitungan detik. Hal tersebut dimungkinkan karena tergantung dengan permintaan dan penawaran antara pembeli saham dengan penjual saham".

Widoatmodjo menyampaikan, "Harga saham merupakan harga atau nilai uang yang bersedia dikeluarkan untuk memperoleh atas suatu saham".

\section{METODE PENELITIAN}

Tempat dilakukannya penelitian adalah di PT. Akasha Wira International Tbk. Dimana penulis mengambil data sekunder yang dapat di akses melalui www.akashainternational.com.

Metode penelitian kuantitatif. Populasinya laporan keuangan dan sampelnya neraca,laporan laba rugi dengan jangka waktu 2008 - 2018. Untuk menganalisis data, penulis menggunakan uji asumsii klasiik. Kemudian regresi, koefisiien determiinasi dan hipotesis. Olah data dengan SPSS..

\section{HASIL DAN PEMBAHASAN}

A. Gambaran Objek Penelitan

Pada tahun 1985 didirikan sebuah perusahaan bernama PT. Alfindo Putra setia. Kemudian setelah ganti nama berkali-kali, perusahaan tersebut merubah namanya dengan PT. Akasha Wira International Tbk. Perseroan bergerak di beberapa bidang usaha. Pada tahun 1986 perusahaan pabrikasi air minum dalam kemasan kemudian perusahaan melebarkan usahanya dengan memproduksi kosmetika untuk perawatan rambut dengan merek Makarizo tahun 2010.

\section{B. Penemuan dan Pembahasan}

\section{Test Classic'sAssuption \\ a. Normality Test}

Pengujian normalitas yang banyak dipakai yaitu Kolmogorov-Smirnov test.

Tabel 3 Hasil Uji Normalitas 
JRNAL ПMПAH

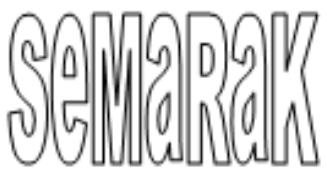

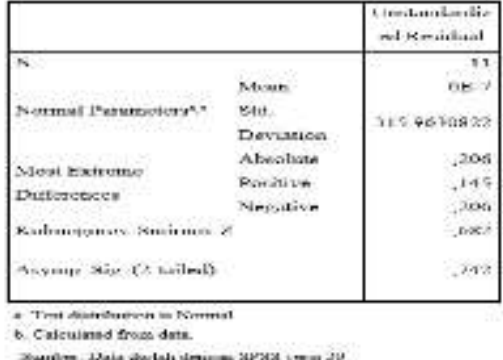

Nilai Asymp. Sig. yaitu 0,742>0.05 dari hasil tersebut dikatakan data berdiistribusi normal.

\section{b. Multikolinieritas Test}

"Pengujian

multikolinearitas bertujuan untuk menguji apakah model regresi ditemukan adanya korelasi antar variabel bebas (Ghozali 2016:103)". Dibawah ini uji multikolinieritas:

\section{Tabel 4 Hasil Uji Multikolinieritas}

\begin{tabular}{|c|c|c|c|}
\hline \multicolumn{2}{|c|}{ Model } & \multicolumn{2}{|c|}{ Collinearity Statistics } \\
\hline & & Tolerance & VIF \\
\hline \multirow{3}{*}{1} & (Constant) & & \\
\hline & DER &, 736 & 1,359 \\
\hline & ROA &, 736 & 1,359 \\
\hline
\end{tabular}

Nilai tolerance 0,736 yaitu $>0.10$ kemudian VIF yaitu 1,359 atau $<10$. Jadi tidak ada multikoliniearitas.

\section{c. Test Heterokedastisitas}

Menurut Widodo (2017:80) "Uji Heteroskedastisitas bertujuan untuk menguji apakah dalam model regresi terjadi ketidaksamaan variansi dari residu satu pengamatan ke pengamatan lain”.

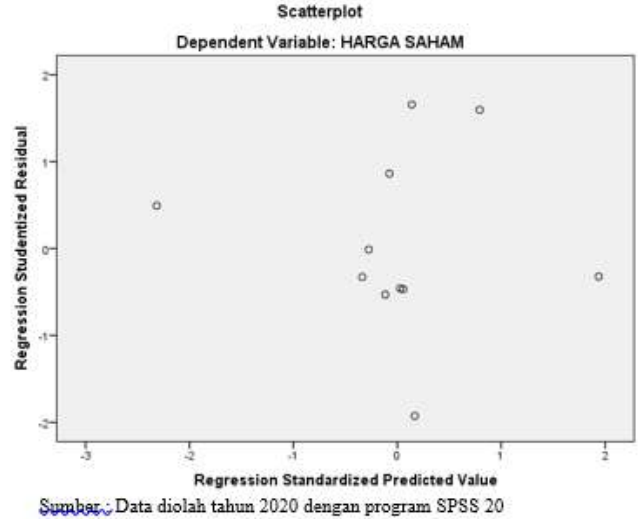

Gambar 1

Uji Heteroskedastisitas

Pada scatter plot, terlihat sebaran datanya berpencar disekitar angka nol serta tidak menciptakan pola tertentu, data ini memenuhi syarat heterokedastisitas.

\section{d. Test Autokorelasi}

Dalam bukunya Ghozali (2016:107) menuliskan, "autokorelasi muncul karena observasi yang berurutan sepanjang waktu berkaitan satu sama lainnya".

Table 5 Hasil Uji Autokorelasi

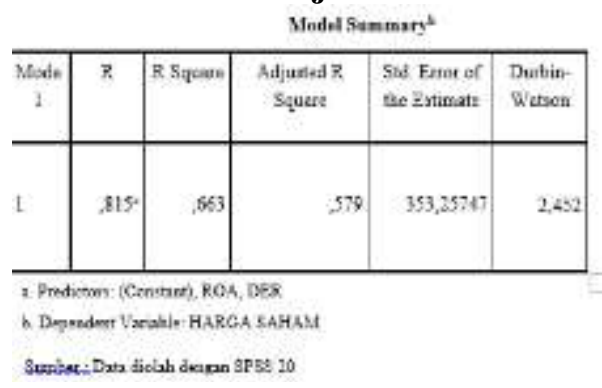

Nilai $D W$ adalah 2,452. Selanjutnya autokorelasi dalam penelitian ini adalah $\mathrm{DU}=1,6044, \mathrm{DW}=2,452$ dan $4-\mathrm{DU}=4$ $1,6044=2,3956$. Maka didapati hasil $1,6044<2,452>2,3956$, yang berarti tidak terdapat gejala autokorelasi.

\section{Pengaruh Secara Partial}

Menurut Sugiyono (2017:184) "Sebagai pembanding untuk melihat pengaruh signifikan, maka digunakan $t_{\text {hitung }}$ dan $t_{\text {tabel }}$ dengan kriteria jika Jika $t_{\text {hitung }}>$ 
JRNAL ПММАH

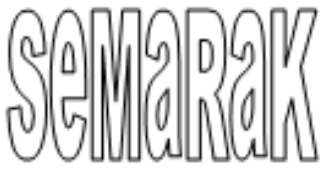

P-ISSN 2615-6849, E-ISSN 2622-3686

Jurnal Semarak,Vol.4,No.2,Juni 2021, Hal (60-66)

@Prodi Manajemen Fakultas Ekonomi Universitas Pamulang $t_{\text {tabe }}$ maka ada pengaruh signifikan dan jika $\mathrm{t}_{\text {hitung }}<\mathrm{t}_{\text {tabel }}$ maka tidak ada pengaruh signifikan".

Table 6 Uji Partial (t)

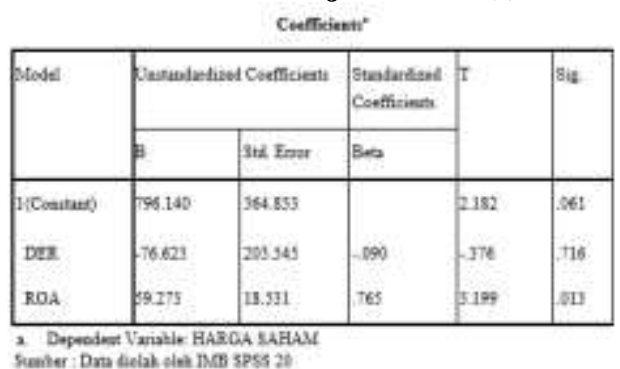

Berdasarkan dari tabel 6 diatas, Variabel "debt to equity ratio" (-0,376 < $2,30600)$ dengan nilai sign. $0,716>0,05$ diartikan "debt to equity ratio" tidak berefek dan tidak sign. atas"harga saham".

Variabel "return on asset" $(3,199$ $>2,30600)$ serta nilai sign. $0,013<0,05$ maka "return on asset" berefek dan sign. atas "harga saham".

\section{Pengaruh Secara Bersamaan (Simultan)}

Menurut Sugiyono (2014:257) "Kriteria penerimaan dan penolakan hipotesis uji $\mathrm{F}$ adalah Jika nilai $\mathrm{F}$ hitung < F tabel maka Ho diterima, dan Ha ditolak dan Jika nilai $\mathrm{F}$ hitung $>\mathrm{F}$ tabel maka Ho ditolak, dan Ha diterima".

Table 7 Uji Simultan (F)

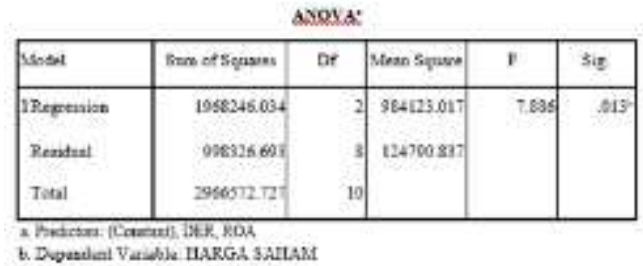

Melihat tabel 7, menunjukkan bahwa nilai $\mathrm{F}_{\text {hitung }}$ sebanyak 7,886 dan $\mathrm{F}_{\text {tabel }}$ 4,459 sehingga $F_{\text {hitung }} 7,886>F_{\text {tabel }} 4,459$ dan nilai sig. $0,013^{\mathrm{b}}<$ tingkat signifikan 0,05 . Maka dinyatakan "debt to equity ratio" dan "return on asset" secara simultan berefek dan sign. atas"harga saham".

\section{Koefiisien Determiinasi (Adjusted $R$ - Squared (R2)}

Menurut Sugiyono (2014:184) "Koefisien determinasi ( $R$ Square $)$ menunujukkan seberapa besar variabel independen menjelaskan variabel dependennya".

Tabel 8 Uji Koefisien Determinasi

\begin{tabular}{|c|c|c|c|c|c|}
\hline \multicolumn{6}{|c|}{ Madel Summung } \\
\hline Model & $R$ & $R$ Syume & $\mid \begin{array}{l}\text { Aquerted } R \\
\text { Square }\end{array}$ & $\begin{array}{l}\text { Sid Error of } \\
\text { the Esclunate }\end{array}$ & $\begin{array}{l}\text { Derbin- } \\
\text { Tavon }\end{array}$ \\
\hline 1 & .8151 & .663 & 579 & 353.25747 & 2.452 \\
\hline
\end{tabular}

Nilai $R$ Square ialah 0,663 (66\%). Hasil menyimpulkan "debt to equity ratio" dan "return on asset" memberikan efek yang kuat atas harga saham. Dimana nilai tersebut berada di interval 60\%-79,9\%.

\section{KESIMPULAN\& SARAN}

A. Kesimpulan

i. עebt to Equity Ratio" tidakberefek signifikan atas "harga saham".

2. "Return on Asset" berefek signifikan atas "harga saham".

3. "Debt to Equity Ratio" dan "Retun On Asset" secara simultan berefek atas"harga saham".

\section{B. Saran}

Adapun saran dan masukan dari peneliti dengan harapan dapat bermanfaat bagi perusahaan adalah sebagai berikut:

1. Perusahaan diharapkan tetap mampu menjaga keseimbangan agar tetap terjaga sesuai dengan tujuan perusahaan. Perusahaan juga harus menjaga sistemnya agar DER dapat ditekan, karena apabila DER meningkat maka berpengaruh menurunnya profitabilitas perusahaan tersebut.

2. Pada rasio keuangan profitabilitas diharapkan tetap mampu dan stabil dalam menjaga keseimbangan antara laba bersih dan asset perusahaan agar tujuan perusahaan dapat tercapai. Diharapkan juga kepada perusahaan untuk menjaga 
JRNAL ПММАH

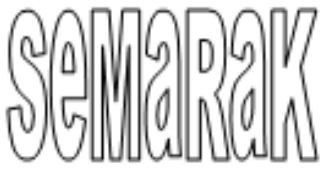

sistemnya agar ROA dapat terus meningkat setiap tahunnya.

3. Salah satu termasuk menurunkan minat investor untuk melakukan investasi adalah besarnya nilai hutang. Oleh sebab itu, perusahaan harus memperhatikan jumlah modal dan hutang karena dapat mempengaruhi keputusan pihak investor dalam berinvestasi.

\section{DAFTAR PUSTAKA}

Darmadji, Tjiptono dan Fakhruddin, H.M. 2012. Pasar Modal Indonesia. Edisi Ketiga. Jakarta

Fahmi , Irham. 2015. Pengantar Manajemen Keuangan Teori dan Soal Jawab. Bandung : Alfabeta

Gunawan, Imam. 2016. Metode Penelitian Kualitatif. Jakarta : Bumi Aksara

Ghozali, Imam. 2016. Aplikasi Analisis Multivariate dengan Program IBM SPSS 23. Edisi Kedelapan. Semarang: Badan Penerbit Universitas Diponogoro

Harahap, Sofyan Syafri, 2013. Analisis Kritis Atas Laporan Keuangan. Jakarta: Rajawali Pers.

Kasmir. 2013. Analisa Laporan Keuangan. Jakarta: PT.Raja Grafindo Persada

Kasmir. 2014. Bank dan Lembaga Keuangan Lainnya. Edisi Revisi 2014. Jakarta: PT. Raja Grafindo Persada

Kasmir. 2015. Analisis Laporan Keuangan. Jakarta: Rajawali Pers.

Kasmir. Dr. 2019. Pengantar Manajemen Keuangan ke tujuh. Jakarta: PT Raja Grafindo Persada.

Sudana, I Made. 2011. Manajemen Keuangan Perusahaan. Jakarta: Erlangga
Sugiyono. 2014. Metode Penelitian Pendidikan Pendekatan Kuantitatif, Kualitatif, dan Kombinasi (Mixed Methods). Bandung: Alfabeta

Sugiyono. 2017. Metode Penelitian Kuantitatif Kualitatif dan $R \& D$. Bandung: Alfabeta.

S.Hermuningsih. 2012. Pengantar Pasar Modal Indonesia. Yoyakarta : UPP STIM YKPN

Widoatmodjo, Sawijid. 2012. Cara Sehat Investasi di Pasar Modal. Edisi Revisi. Jakarta: PT. Jurnalindo Aksara Grafika.

\section{Sumber Jurnal:}

Amthy Suraya dan Juni.2020. “ Pengaruh Return On Asset (ROA) Dan Earning Per Share (EPS) Terhadap Harga Saham Pada PT. Ultrajaya,Tbk Tahun 2010-2016. Jurnal Ilmiah Prodi Manajemen Universitas Pamulang, Vol 8,No 1.

Dede Hendra. 2019. "Pengaruh Debt to Equity Ratio (DER), Current Ratio(CR), Return On Asset (ROA), dan Return On Equity (ROE), terhadap Harga Saham dan Implikasinya terhadap Return Saham pada Industri Penerbangan (Studi Kasus pada Perusahaan Maskapai ASIA)" Jurnal Ilmiah

Hadijah Febriana. 2018 "Pengaruh Penyaluran Kredit, CAR (Capital Adequacy Ratio), NPL (Non Performing Loan) Terhadap Pendapatan Bunga dan Dampaknya Terhadap Profitabilitas (Studi Kasus pada BANK Pembangunan Daerah yang Terdaftar di BEI) " Jurnal Sekuritas

Irnawati, J (2019). Pengaruh Return On Assets (ROA), Return On Equity (ROE), dan Current Ratio (CR) Terhadap Nilai Perusahaan dan Dampaknya Terhadap Kebijakan Deviden, Jurnal Sekuritas Unpam, 
JRNAL ПMПAH

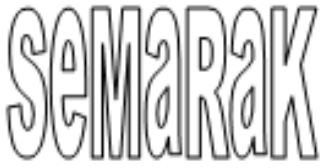

P-ISSN 2615-6849, E-ISSN 2622-3686

Jurnal Semarak,Vol.4,No.2,Juni 2021, Hal (60-66)

@Prodi Manajemen Fakultas Ekonomi Universitas Pamulang
Purnomo, S., \& Pasaribu, V. L. D. (2019). Pergerakan Harga Saham Pt Adaro Energy Tbk (Adro) Pada Pengumuman Dividen Interim Tahun Buku 2018. Jurnal Ekonomi Efektif, 2(1).

Siti Nur'aidawati. 2018. "Pengaruh Current Ratio (CR), Total Asset Turn Over (TATO), Debt To Equity Ratio (DER) Dan Return On Asset (ROA) Terhadap Harga Saham Dan Dampaknya Pada Nilai Perusahaan ( Studi Kasus Pada Sepuluh Bank Terbesar Yang Terdaftar Di Bursa Efek Indonesia Periode Tahun 2011 2015)" Jurnal Sekuritas.

Neneng Tita Amalya. 2018. "Pengaruh Return On Asset (ROA), Return On Equity (ROE), Net Profit Margin (NPM) Dan Debt To Equity Ratio (DER) Terhadap Harga Saham" Jurnal Sekuritas..

Reza Octovian, Sahrunisa Sahrunisa. 2020. "Pengaruh Debt To Equity Ratio (DER), Price To Earning Ratio (PER) Dan Inventory Turn Over Ratio Terhadap Harga Saham Pada PT Lippo Cikarang Tbk Periode 2009-2018." JIF

SUTIMAN, S. (2020). PENGARUH SET PELUANG INVESTASI, RASIO PEMBAYARAN DIVIDEN DAN BEBAN KEUANGAN TERHADAP PRICE BOOK VALUE PADA PERUSAHAAN MANUFAKTUR YANG TERDAFTAR DI BURSA EFEK INDONESIA PERIODE 20122016. JURNAL SeMaRaK, 3(1), 2740.

Gatot Kusjono, Fegi Patricia Carolin.2020. "Pengaruh Likuiditas Dan Solvabilitas Terhadap Return Saham Pada PT. UNILIVER INDONESIA (PERSERO) Tbk,Periode 2011-2018. Jurnal Ilmiah
Feasible: Bisnis Kewirausahaan \& Koprasi, Vol 2.No.1.

Wartono, T., Tumanggor, M., Oktrima, B., \& Delimah, V. L. (2021, January). Analysis of Ratio and Financial Performance of Open Company Pharmaceutical Industry Which has Been Listing in Indonesia Stock Exchange (Case Study in Pharmaceutical Company PT. Kimia Farma. Tbk). In INCEESS 2020: Proceedings of the 1st International Conference on Economics Engineering and Social Science, InCEESS 2020, 17-18 July, Bekasi, Indonesia (p. 268). European Alliance for Innovation. 